\title{
Matrix metalloproteinase- 9 in the pathophysiology and diagnosis of dry eye syndrome
}

This article was published in the following Dove Press journal:

Metalloproteinases In Medicine

17 March 2017

Number of times this article has been viewed

\author{
Stephen C Pflugfelder \\ Fang Bian \\ Cintia S de Paiva \\ Department of Ophthalmology, \\ Baylor College of Medicine, Houston, \\ TX, USA
}

\begin{abstract}
Dry eye and tear dysfunction are common ocular disorders that cause cornea barrier disruption resulting in a poorly lubricated and irregular cornea epithelium, eye irritation and blurred vision. Increased levels and activities of matrix metalloproteinases (MMPs), particularly MMP-9, have been detected in the tears and ocular surface epithelial and inflammatory cells in dry eye. MMPs have been found to participate in disruption of tight junctions in the apical cornea epithelium leading to their accelerated desquamation and barrier disruption. This review summarizes evidence showing the contribution of MMPs to dry eye pathogenesis and their roles as biomarkers and therapeutic targets.
\end{abstract}

Keywords: matrix metalloproteinase, dry eye, keratitis sicca, cornea, barrier function, Sjögren syndrome

\section{Dry eye overview}

Dry eye and tear dysfunction are common ocular disorders that cause cornea barrier disruption resulting in a poorly lubricated and irregular cornea epithelium, eye irritation and blurred vision. It affects millions of people worldwide and is one of the most frequent conditions for which patients seek eye care. ${ }^{1}$ Aging and female sex are significant risk factors for dry eye which increases in prevalence around the fifth decade, with further increase every decade thereafter. ${ }^{2-13}$ Prevalence of dry eye varies from $2 \%$ to $50 \%$, depending on the population studied and the diagnostic criteria for dry eye (symptom questionnaire vs. objective signs). ${ }^{1-3,6,7,9-11,14-23}$ There is scarce information about the natural history of dry eye, but there is a recognized disconnection between signs and symptoms; patients tend to be more symptomatic at early stages..$^{24,25}$ Dry eye causes corneal irregularity ${ }^{26-28}$ and decreases functional vision by altering contrast sensitivity ${ }^{29-31}$ and, therefore, decreases quality of life with a significant burden on the individual as well as the society. ${ }^{23,32-35} \mathrm{~A}$ meta-analysis of 22 published studies showed increased odds ratio for depression and anxiety in patients with ocular Sjögren syndrome (SS).$^{36}$ There is increased evidence that dry eye is an inflammatory disease, and this review will focus on matrix metalloproteinases (MMPs) and their role in the pathogenesis of dry eye.

\section{Cornea barrier disruption is a feature of dry eye}

As the principal lens of the eye, the cornea has unique features to maintain its transparency and smooth surface that include a lack of blood vessels and a multilayered stratified, non-cornifying epithelium. The differentiated apical epithelial cells produce
Correspondence: Stephen C Pflugfelder Department of Ophthalmology, Cullen Eye Institute, Baylor College of Medicine, 6565 Fannin St, NC505, Houston, TX

Tel + I 7137986100

Fax +I 7137981457

Email stevenp@bcm.edu 
heavily glycosylated transmembrane mucins (MUC1, MUC4 and MUC16) that associate with carbohydrate-binding proteins in tears, particularly galectin 3 , to form a glycocalyx that maintains hydration and surface smoothness. ${ }^{37}$ The cornea epithelium also serves as a barrier to adverse environmental conditions, microbial pathogens and immunogens/allergens. Paracellular barrier is maintained by tight junctions in the apical epithelium, while the transcellular barrier is provided by transmembrane mucins and their bound O-glycans in the glycocalyx. ${ }^{37}$

MMPs have been found to perturb or disrupt the corneal epithelial barrier by cleaving a variety of substrate molecules involved in barrier maintenance, including occludin (MMP-9), galectin 3 (MMP-2 and -9) and MUC16 (MMP-7). ${ }^{38-40}$ Gelatinases have been implicated in physiologic desquamation of the cornea epithelium. Decreased corneal epithelial desquamation in vitamin A-deficient rats was associated with significantly decreased MMP-2 and -9 expression. ${ }^{41}$ A study showed clusters of disrupted tight junction proteins, occludin and claudin, in conjunction with increased MMP-2 immunoreactivity in samples of superficial cornea epithelium obtained at night in Xenopus laevis. ${ }^{42}$ While this mechanism for corneal epithelial desquamation has not been confirmed in human corneas, increased levels of MMP-2 and -9 have been found in cornea epithelium and tear fluid obtained from eyes with recurrent corneal epithelial erosion, ${ }^{43,44}$ and increased proand active forms of MMP-9 have also been found in tears sampled from the closed eye during sleep when recurrent erosions typically occur while tear production and clearance are decreased. ${ }^{45}$

There is mounting evidence that MMPs contribute to the altered cornea barrier function that is observed in dry eye. ${ }^{46-48}$ Increased cornea epithelial permeability to fluorescent dyes is observed in human dry eye (sodium fluorescein) and experimental mouse models (fluorescent dextran conjugates). ${ }^{48,49}$ Exposure to desiccating stress increased MMP-9 expression and activity in the corneal epithelium and was found to lyse the tight junction protein occludin in the apical corneal epithelium, leading to increased permeability to the tracer molecule $70 \mathrm{kDa}$ Oregon Green dextran in mice. ${ }^{48,50,51}$ An important component of the glycocalyx, galectin 3, is an MMP-9 substrate. ${ }^{39,52}$ MMP-7 has been reported to cleave MUC16, the principal mucin constituent of the cornea epithelial glycocalyx, from cultured human cornea epithelial cell membranes. ${ }^{40}$ Taken together, these findings implicate MMPs in the disruption of molecules maintaining para- and transcellular cornea barrier.

\section{Cornea epitheliopathy in dry eye}

Among the most exposed mucosal surfaces in the body, the cornea and conjunctiva depend on tear production by the lacrimal functional unit to maintain hydration, smoothness and optical clarity. ${ }^{53}$ Among the myriad of proteins in the tears are anti-inflammatory molecules, including cytokine antagonists (e.g., interleukin [IL]-1RA), tissue inhibitors of MMPs (TIMPs) and clusterin (CLU). ${ }^{47,54-59}$ Disease or dysfunction of the lacrimal functional unit alters the balance of MMPs and their inhibitors and stimulates activation of innate inflammatory pathways in the ocular surface epithelium and resident immune/inflammatory cells. A key stimulus is increased tear osmolarity, primarily due to increased tear sodium ion concentration. ${ }^{60,61}$ Osmotic stress has been found to activate cell signaling pathways, such as the mitogen-activated protein kinases (MAPK) and the nuclear factor kappa $\mathrm{B}\left(\mathrm{NF}_{\mathrm{k}} \mathrm{B}\right)$ pathways, that stimulate production of MMP-9 and its physiologic activator (e.g., MMP-3 ${ }^{47,62,63}$ ), as well as inflammatory cytokines such as IL-1 $\beta$ that also stimulate MMP production. ${ }^{62,64,65}$ Lacrimal dysfunction also results in reduced tear concentrations of TIMPs and CLU. ${ }^{56,66}$

Increased MMP-9 activity in the epithelium and tears promotes lysis of tight junction proteins and accelerates detachment of apical corneal epithelial cells, exposing less-mature subapical epithelial cells that lack a developed glycocalyx. ${ }^{38}$ The irregular cornea surface with disrupted permeability barrier in dry eye reduces visual performance, causes irritation due to decreased surface lubrication and increases blink frequency that can exacerbate inflammation and protease activity (Figure 1).

\section{Correlations between MMP-9 and severity}

Tear MMP-9 level or activity has been evaluated in tear samples from normal subjects and dry eye patients using a variety of methods (Table 1). Using a point-of-care lateral flow immunoassay (InflammaDry ${ }^{\circledR}$; Rapid Pathogen Screening, Sarasota, FL, USA), which detects both pro- and active MMP-9 at tear concentrations $\geq 40 \mathrm{ng} / \mathrm{mL}$, elevated tear MMP-9 was found to have high sensitivity and specificity with clinical diagnosis of dry eye in two studies, and in another study, a positive result was significantly correlated with severity of irritation symptoms and ocular surface dye staining, tear break-up time and systemic autoimmune disease, particularly SS. ${ }^{67-69}$ Using the same assay, Lanza et al found only $39 \%$ of subjects with symptoms of dry eye had a positive MMP-9 assay and there was no difference in the profile of signs and symptoms between MMP-9-positive and 


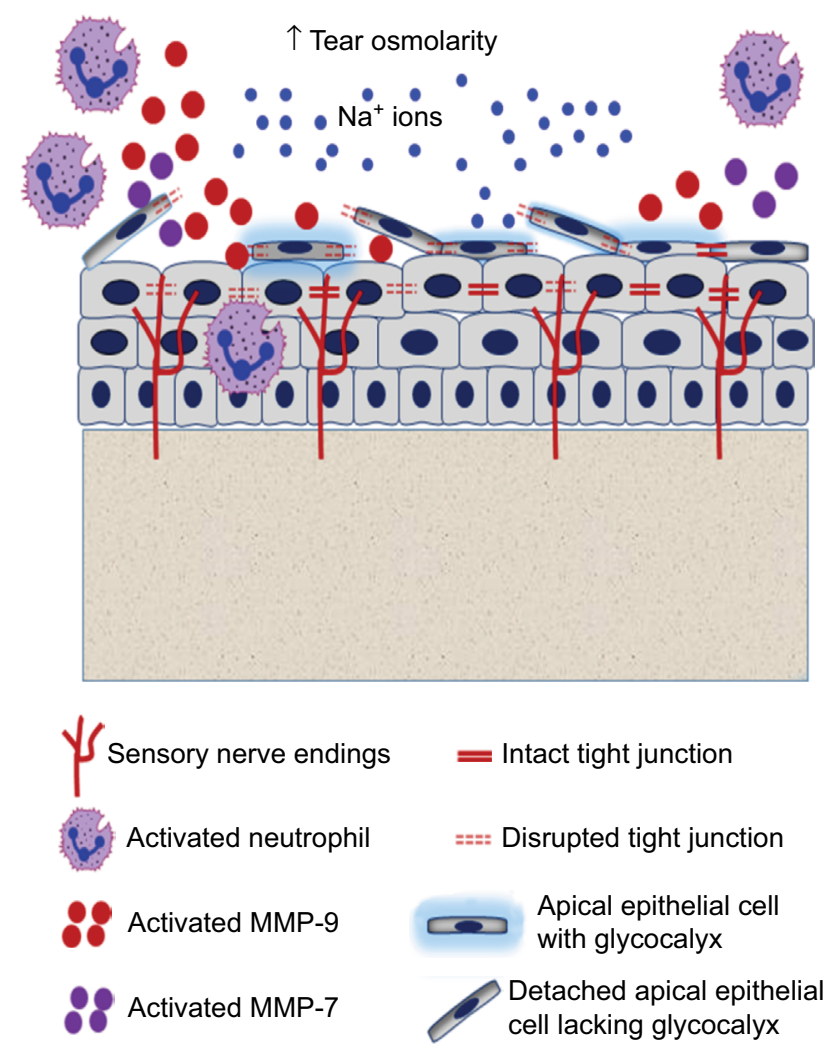

Figure I Desiccation increases the tear osmolarity and the concentrations of inflammatory cytokines in the tears and stimulates the ocular surface epithelial cells and neutrophils to produce and secrete latent MMPs.

Notes: These MMPs, once activated by other proteases, digest substrates on the ocular surface. These include tight junction proteins, such as occludin, in the apical epithelial cells and galectin-3, a key component of the glycocalyx. Loss of tight junctions leads to accelerated epithelial desquamation, cornea barrier disruption and exposure of corneal nociceptors which results in cornea pain. Activated MMP-7 has been found to lyse the membrane mucin $\mathrm{MUCl} 6$ that is a key component of the corneal epithelial glycocalyx.

Abbreviation: MMPs, matrix metalloproteinases.

-negative subjects. ${ }^{70}$ Using a quantitative immunobead assay, tear MMP-9 concentration was directly correlated to tear osmolarity and inversely correlated to Schirmer test scores that are a measure of tear production..$^{71}$ In a study measuring tear MMP-9 activity rather than concentration, MMP-9 activity increased with categorical severity of tear dysfunction using the Dry Eye Workshop (DEWS) criteria and tear MMP-9 activities showed significant positive correlation with symptom severity scores, corneal and conjunctival fluorescein staining, topographic surface regularity index and percentage area of abnormal superficial corneal epithelia measured by confocal microscopy, and inverse correlation with low-contrast visual acuity and fluorescein tear break-up time. $M M P-9$ gene expression and immunoreactivity were also found elevated in conjunctival epithelial cells obtained from normal subjects and patients with SS-associated dry eye and meibomian gland disease (MGD) that also causes tear instability. ${ }^{72}$ Levels of MMP-9 transcripts were significantly higher in both types of tear dysfunction than asymptomatic controls, and MMP-9 expression was higher in SS than MGD. MMP-9 expression significantly correlated with clinical severity in the SS group. Additionally, corticosteroid treatment significantly reduced MMP-9 expression in both groups.

Significantly higher concentration of MMP-9 was found in eyes with conjunctivochalasis (a condition of conjunctival redundancy that alters tear distribution, clearance and stability), and active MMP-9 was the most abundant form in tear samples from these patients. MMP-9 significantly decreased after surgical resection of the redundant conjunctiva. ${ }^{73}$ Increased MMP-8 and -9 concentrations and decreased TIMP-1 concentration were also reported in tears from patients with the fibrotic ocular surface inflammatory diseases, Stevens-Johnson syndrome (SJS) and ocular cicatricial pemphigoid (OCP), with the highest MMP-9 concentration in SJS. MMP-8/TIMP-1 and MMP-9/TIMP-1 ratios were markedly elevated in both SJS and OCP groups (SJS $>\mathrm{OCP}$ ) compared to controls. ${ }^{74}$ Across all study groups, MMP-9 was strongly correlated with MMP-8 and myeloperoxidase levels, suggesting that neutrophils are the primary source of the tear MMP-9 in these conditions.

In addition to the association between MMPs and ocular surface diseases, Aluri et al found significantly higher protein expression and activities of MMP-2 and -9 in the lacrimal glands of two mouse models of SS (MRL/lpr and NOR/LtJ strains) compared to wild-type strains. ${ }^{75}$ MMP-2/-9 inhibitor peptide treatment of MRL/lpr mice improved aqueous tear production and decreased the number and size of lymphocytic foci in the inflamed lacrimal glands. ${ }^{75}$

\section{Effects of MMP-9 gene deletion or inhibition on corneal epithelial disease in mouse models}

The role of MMP-9 in dry eye was further confirmed using gene knock-out (KO) and inhibitors in murine models. MMP-9 was found to disrupt corneal epithelial tight junction proteins both in vitro and in vivo and participate in acute corneal barrier disruption in the desiccating stress dry eye model..$^{38,47,48,63,76,77}$ MMP-9KO was noted to be resistant to dry eye-induced corneal changes, but exogenous administration of recombinant MMP-9 recapitulated the acute corneal barrier changes observed with wild-type mice.

\section{Combined alkali burn and dry eye}

Corneal alkali burns are devastating injuries with potentially blinding consequences, where MMPs have been implicated..$^{7-81}$ Because the high-airflow, low-humidity controlled environments that we all live and work in are an 
Table I MMP-9 in dry eye

\begin{tabular}{|c|c|c|}
\hline Authors & $\begin{array}{l}\text { Sample/method of MMP-9 } \\
\text { detection }\end{array}$ & Findings \\
\hline Acera et $\mathrm{al}^{73}$ & ELISA, zymography & $\begin{array}{l}\text { MMP-9 concentration was significantly increased in eyes with conjunctivochalasis with } \\
\text { and without dry eye; MMP-9 was activated in these eyes }\end{array}$ \\
\hline Arafat et $\mathrm{al}^{74}$ & Multiplex immunobead assay & $\begin{array}{l}\text { Increased MMP-8 and }-9 \text { and decreased TIMPI concentration in tears from SJS and } \\
\text { OCP (SJS>OCP) }\end{array}$ \\
\hline Aragona et $\mathrm{al}^{72}$ & RT-PCR and immunostaining & $\begin{array}{l}\text { MMP-9 transcripts were significantly higher in conjunctiva from SS and MGD } \\
\text { (SS>MGD) than asymptomatic controls. MMP-9 expression significantly correlated } \\
\text { with clinical severity in SS. Corticosteroid significantly reduced MMP-9 expression }\end{array}$ \\
\hline Chotikavanich et al & $\begin{array}{l}\text { Tears/enzyme activity assay } \\
\text { Conjunctival epithelium/mRNA by } \\
\text { RT-PCR }\end{array}$ & $\begin{array}{l}\text { Progressive increase in tear activity with severity and significant positive correlation } \\
\text { with irritation symptoms and corneal disease; conjunctival gene transcripts } \\
\text { significantly increased }\end{array}$ \\
\hline Lanza et $\mathrm{al}^{70}$ & Tears/lateral flow immunoassay & $\begin{array}{l}39 \% \text { positive in symptomatic patients, no difference in profile of dry eye signs and } \\
\text { symptoms between MMP-9-positive and -negative subjects }\end{array}$ \\
\hline Messmer et $\mathrm{al}^{69}$ & Tears/lateral flow immunoassay & $\begin{array}{l}40 \% \text { of dry eye patients MMP- } 9 \text { positive; significant correlation between MMP-9 and } \\
\text { irritation symptoms, tear break-up time, ocular surface dye staining and systemic } \\
\text { autoimmune disease, particularly SS }\end{array}$ \\
\hline Sambursky et al ${ }^{68}$ & Tears/lateral flow immunoassay & $\begin{array}{l}\text { Sensitivity of } 85 \% \text { and sensitivity of } 94 \% \text { for dry eye diagnosis, compared to clinical } \\
\text { assessment }\end{array}$ \\
\hline Sambursky et al ${ }^{67}$ & Tears/lateral flow immunoassay & $\begin{array}{l}\text { Sensitivity of } 81 \% \text { and sensitivity of } 98 \% \text { for dry eye diagnosis based on signs and } \\
\text { symptoms; sensitivity of } 86 \% \text { and sensitivity of } 97 \% \text { for dry eye diagnosis based on } \\
\text { signs only }\end{array}$ \\
\hline VanDerMeid et $\mathrm{al}^{71}$ & Tears/immunobead assay & $\begin{array}{l}\text { Among five MMPs (I, 2, 7, } 9 \text { and } 10), \text { MMP-7 and }-9 \text { had the highest concentration; } \\
\text { MMP-9 was inversely correlated with tear production and positively correlated with } \\
\text { tear osmolarity }\end{array}$ \\
\hline
\end{tabular}

Abbreviations: ELISA, enzyme-linked immunosorbent assay; MGD, meibomian gland disease; MMPs, matrix metalloproteinases; OCP, ocular cicatricial pemphigoid; mRNA, messenger RNA; RT-PCR, reverse transcriptase polymerase chain reaction; SJS, Stevens-Johnson syndrome; SS, Sjögren syndrome; TIMP, tissue inhibitors of MMPs.

underrecognized source of desiccation, we created a more severe model of alkali burn by subjecting mice to desiccating stress immediately after creation of the corneal alkali burn. ${ }^{82-85}$ This simulated the most severe burn cases, where extensive facial and eyelid thermal injury results in eye exposure and desiccation due to loss of protection from the eyelids and reduced blinking. We found there was an additive pathogenic effect of dry eye to alkali burn, with amplification of MMP-3, -8, -9 and -12, IL-6 and IL-1 $\beta$ mRNA expression and sterile corneal perforation in $\sim 30 \%$ of animals subjected to the chemical burn and desiccating conditions.$^{82}$ There was a significant tenfold increase in MMP-9 mRNA levels and a twofold increase in MMP-9 activity in alkali burn plus desiccation corneas, compared to the dry eye alone group. ${ }^{82}$ These results demonstrate that MMPs contribute to the desiccation-induced worsening of cornea disease in conditions of severe inflammation.

\section{MMP-9 as a diagnostic biomarker}

InflammaDry is a rapid ( $<10 \mathrm{~min})$ innovative immunoassay test to measure MMP-9 tear concentration in tears, which was designed to be used in the office by medical doctors, nurse or ancillary staff. Tear samples are collected from the inferior meniscus and palpebral conjunctival by dabbing the surface with a collecting fleece that is assembled with the test cassette after adding the assay buffer. The test is positive (meaning MMP-9 concentration is $\geq 40 \mathrm{ng} / \mathrm{mL}$ ) when two lines (one blue and one pink) are visualized in the test window. A blue line indicates that the tear concentrations are $<40 \mathrm{ng} / \mathrm{mL}$. The advantages of this assay are its ease of use and the rapid time to obtain results. Because it is nonquantitative, patients with high MMP-9 levels will have the same test result as those with moderately high levels, as once the threshold concentration of MMP-9 is detected, the pink line will be present. When Sambursky et al evaluated 206 patients with dry eye, they reported a sensitivity of $85 \%$, specificity of $94 \%$, negative predictive value of $73 \%$ and positive predictive value of $97 \%$ using the InflammaDry test. ${ }^{68}$

The clinical trials summarized in Table 1 show conflicting results regarding the diagnostic utility of the InflammaDry tear MMP-9 immunoassay. This may be due to the design of this test that detects a threshold MMP-9 concentration. Since correlation has been found between level of MMP-9 gene expression and tear activity and clinical severity of dry eye disease (DED), it is possible that patients with mild disease may have tear MMP-9 concentrations above normal levels, but below this threshold level. This points to the need for a quantitative assay that measures MMP-9 protein, preferably 
latent and activated forms, or MMP-9 activity. None of the commercially available assays that have been used in reported clinical trials are currently approved for clinical diagnosis, but results of these studies show the potential of these technologies.

\section{Therapeutic effects of MMP-9 inhibitors on cornea disease of dry eye}

There is no specific MMP-9 inhibitor with an approved indication to treat dry eye. However, anti-inflammatory therapy with doxycycline, azithromycin or the corticosteroid dexamethasone has shown promising results in preclinical studies and in human trials as off-label drugs, and the Food and Drug Administration (FDA)-approved dry eye therapy cyclosporine A (CsA) emulsion has been found to inhibit MMP production. All of these agents are currently used to treat dry eye, and their efficacy in improving the corneal epithelial disease of dry eye is presented in more detail below. To the best of the authors' knowledge, there have been no clinical trials investigating the efficacy of selective MMP-9 inhibitors in dry eye.

\section{Doxycycline and azithromycin Doxycycline}

Doxycycline, a tetracycline antibiotic with potent anti-inflammatory properties in subantimicrobial doses, has been shown to inhibit MMPs in vitro. ${ }^{86-91}$ Doxycycline has been found to decrease activation of the MAPK and $\mathrm{NF}_{\mathrm{k}} \mathrm{B}$ pathways and improve corneal barrier function and the number of mucusproducing conjunctival goblet cells in dry eye. ${ }^{48,62,65,92-95} \mathrm{We}$ and others have tested different preparations of doxycycline in our mouse desiccating stress dry eye model, and we have shown significant improvement in corneal barrier function (reduced uptake of a fluorescent dye) and decreased transcript levels of inflammatory cytokines such as IL-1 $\beta$, IL-6, tumor necrosis factor-a and MMPs. ${ }^{48,50,77,92,96,97}$ Similar results were obtained with a variety of formulations, including topically applied doxycycline dissolved in saline or hydroxypropyl methylcellulose, glycerin and excipients, or subconjunctival injections of doxycycline nanoparticles. ${ }^{77,96,97}$ We also observed that topical administration of doxycycline decreased apical corneal epithelial desquamation that is accelerated in desiccating stress and it preserved corneal normal architecture. ${ }^{96}$ Doxycycline increased the rate of corneal epithelial wound healing and decreased MMP-13 and -9 mRNA transcripts, MMP-9 activity and immunoreactivity in the combined model of alkali burn and dry eye. ${ }^{98}$ This was accompanied by a decrease in production of neutrophil gelatinase-associated lipocalin (NGAL)-MMP-9 formation and lower levels of IL-1 $\beta$.

The greatest challenge with topical delivery of doxycycline is its rapid oxidation when exposed to environmental oxygen, which limits its stability and potency. Oral doxycycline has also been used off-label to treat recurrent corneal erosions, ocular rosacea and MGD, ${ }^{99-102}$ as well as other inflammatory diseases where MMPs are implicated, including rheumatoid arthritis, and atherosclerotic cardiovascular disease. ${ }^{103}$ It is FDA approved to treat periodontitis, a disease of the gums where increased levels of MMPs are found. However, side effects of oral administration, such as gastrointestinal upset, photosensitivity and vaginal candidiasis, can occur.

\section{Azithromycin}

Azithromycin is a macrolide antibiotic that is used for treating a variety of bacterial and chlamydial infections. Like doxycycline, it is also recognized as having anti-inflammatory effects by suppressing cytokine and MMP-9 production by airway epithelial cells. Azithromycin is currently used orally and topically to treat ocular rosacea and MGD. Azithromycin inhibited production of inflammatory cytokines, chemokines and MMP-1, -3 and -9 in cultured human corneal epithelial cells (HCEC) stimulated by the toll like receptor 2 (TLR2) ligand, zymosan. ${ }^{104}$ Azithromycin inhibited production of all of these MMPs in a dose-dependent fashion, showing greater reduction in MMP-9 production by zymosan-stimulated HCEC than anti-TLR2 antibody or an $\mathrm{NF}_{\mathrm{k}} \mathrm{B}$ inhibitor. The effects of 4 weeks of topical azithromycin 1\% therapy were evaluated on the mRNA expression of a variety of inflammatory mediators, including MMP-9, in conjunctival epithelial cells of patients with MGD. ${ }^{105}$ MMP-9 activity was also measured in the tears. At baseline prior to initiating therapy, levels of MMP-9 transcripts in the conjunctival epithelium were 13.5-fold higher in MGD samples than those from normal eyes. Following 4 weeks of azithromycin treatment, MMP-9 expression significantly decreased toward normal levels, although it rebounded toward pretreatment values 4 weeks after cessation of azithromycin. Change in tear MMP-9 activity was similar to the pattern observed for MMP-9 transcripts.

\section{Osmoprotectants}

As noted above, elevated tear osmolarity is a common feature of tear dysfunction. Osmotic stress is a potent inflammatory stimulus on the ocular surface epithelial cells, which is of similar magnitude to stimulation with lipopolysaccharide. Artificial tears are the first-line therapy of dry eye, and these 
typically contain one or more lubricating polymers plus additives. Among the additives are molecules that protect against osmotic stress. The effects of three osmoprotectants (1-carnitine, erythritol, betaine) on inhibiting stimulated expression of collagenase MMP-13, gelatinases MMP-2 and -9, stromelysin MMP-3, and matrilysin MMP-7 in HCEC by hyperosmotic media were also investigated. ${ }^{106}$ Osmotic stress significantly stimulated mRNA expression of all of these MMPs in an osmolarity-dependent fashion. 1-Carnitine significantly suppressed the expression of all of the MMPs except MMP-2, and erythritol and betaine significantly suppressed MMP -2, -7 and -9. Gelatin zymography showed that all three osmoprotectants inhibited activation of MMP-2 and -9.

\section{Corticosteroids}

Dexamethasone, a prototype corticosteroid, has been used topically in murine models of dry eye with great success. We have shown that its topical administration four times per day during experimental exposure to desiccating stress decreases MAPKs (notably the june amino-terminal kinase [JNK] pathway); blunts the production and activity of MMPs and also inflammatory cytokines and chemokines, compared to saline control. ${ }^{77}$ Also, in vitro, dexamethasone has been shown to inhibit the interferon-Y-induced endoplasmic reticulum stress and unfolded protein response in cultured conjunctival goblet cells, preserving mucin production. ${ }^{107} \mathrm{~A}$ biodegradable dexamethasone-loaded nanowafer used once a day on alternate days in the desiccating stress model showed similar or better control of inflammation and corneal barrier disruption, compared to topically administered dexamethasone solution four times per day, demonstrating not just greater efficacy but also the potential for improved patient compliance due to the reduced dosing frequency. ${ }^{108}$ Application of topical $0.1 \%$ dexamethasone four times per day showed a positive effect in the combined model of alkali burn and desiccating stress, by significantly decreasing mRNA and protein levels of MMP-1, -3, -9 and -13, decreasing MMP-9 gelatinolytic activity and NGAL-MMP-9 complex formation, while causing an impressive improvement in corneal opacification and preventing corneal perforation, compared to saline controls. ${ }^{98}$ Studies with gene KO and pharmacologic inhibitors showed that part of the beneficial effects from dexamethasone in this model were through an increase in MMP- $8{ }^{84}$

Nonpreserved topical methylprednisolone administered three to four times per day significantly improved signs and symptoms of dry eye in patients with SS. ${ }^{109}$ Clinically, prolonged use of topical corticosteroids is plagued by frequent side effects, such as cataract induction and glaucoma, that limit their wide use in dry eye; ${ }^{109}$ however, the introduction of "soft-steroids" that carry a markedly reduced risk of sightthreatening side effects has led to community acceptance of corticosteroid therapy on a limited basis. ${ }^{110,111}$

Topical treatment with $0.1 \%$ dexamethasone for 2 weeks prior to a low-humidity exposure stress using specially designed goggles significantly decreased corneal and conjunctival staining, improved blink rate and decreased Human leukocyte antigen - D related (HLA-DR) RNA levels in conjunctiva of patients with aqueous deficient dry eye. ${ }^{112}$ Significant improvement in signs and symptoms of dry eye were observed after 3 weeks of topical $0.1 \%$ fluorometholone therapy in dry eye patients subjected to a 2 -hour challenge in a controlled adverse environment exposure, ${ }^{113}$ which increases the concentrations of MMP-9 and other inflammatory markers in tears. ${ }^{114}$

\section{CsA}

CsA was first discovered in 1976 as a weak antimycotic agent produced by the soil fungus Tolypocladium inflatum, and it was subsequently found to have immunomodulatory properties that led to its widespread use as an immunosuppressant to prevent rejection of solid organ transplants. ${ }^{115,116}$ After topically applied CsA was found to be an effective treatment for canine keratoconjunctivitis, it was also noted to improve human DED and a $0.05 \%$ emulsion received FDA approval to treat dry eye-associated inflammation in 2002. ${ }^{117,118}$ Since then, the medication has been widely used to treat millions of dry eye patients, and a recent comprehensive review describes its efficacy in DED. ${ }^{119} \mathrm{CsA}$ is a calcineurin inhibitor that impairs $\mathrm{T}$ cell activation and cytokine production. CsA not only strikingly increases conjunctival goblet cell (GC) numbers in humans and animal models of dry eye, but also decreases epithelial apoptosis. ${ }^{118,120-126}$ By doing so, it has an indirect effect on the ocular surface by increasing the production of immunomodulatory factors by conjunctival goblet cells. ${ }^{127,128}$ CsA has been shown to decrease MMP-2, $-3,-9$ and -13 production and activity in cultured human gingival and pterygium fibroblasts. ${ }^{129-131}$ Topical CsA treatment was found to improve thyroid orbitopathy-related dry eye symptoms and decreased MMP-9 expression in conjunctival epithelial cells obtained from patients with thyroid orbitopathy. ${ }^{132}$ Results from a retrospective study where patients were treated with 2,000-4,000 mg of oral omega-3 fatty acids and artificial tear replacement with and without CsA emulsion showed that $85 \%$ of patients using CsA reported at least $50 \%$ improvement in symptoms. About $50 \%$ of these showed conversion from a positive to negative InflammaDry test, suggesting that CsA decreased MMP-9 concentration in the tears of these patients..$^{133}$ 


\section{CLU}

CLU is a glycoprotein produced and secreted by the mucosal epithelia; it is cytoprotective, anti-inflammatory and serves as an extracellular chaperone that inhibits the activity of MMPs, including MMP-2, -3, -7 and -9. CLU inhibited MMP-9mediated lysis of epithelial tight junctions in the MCF-7 mammary epithelial cell line. Furthermore, the desiccating stress mouse model of dry eye depleted CLU in the ocular surface epithelium. ${ }^{134}$ In a subsequent study from the same group, using the same mouse dry eye model, CLU prevented and reversed corneal epithelial barrier disruption by sealing the epithelial surface in a critical all-or-none concentration fashion. ${ }^{56}$ When the CLU level was decreased below the critical all-or-none threshold, the cornea barrier again became vulnerable to desiccating stress. CLU was found to bind to the surface of desiccated corneas, and in vitro, to galectin 3 , a key component of the corneal epithelial glycocalyx that maintains transcellular barrier function.

\section{Conclusion}

In summary, this review presents evidence from animal models and clinical trials that clearly supports a role for MMPs in the pathogenesis of dry eye-induced corneal disease and indicates that MMP-9 is a valid biomarker of ocular surface inflammation and severity of DED, as well as a diseaserelevant therapeutic target.

\section{Acknowledgments}

This work was supported by NIH grant EY11915 (SCP), DoD award 5W81XWH-13-1-0146 (SCP), W81XWH-12-1-0616 (CSdP), NIH core grants (EY002520, EY020799 and CA125123), NIH training grant T32 AI053831 (FB), NIH funding to Cytometry and Cell Sorting Core at Baylor College of Medicine (NIAID P30AI036211, NCI P30CA125123 and NCRR S10RR024574), Biology of Inflammation Center Baylor College of Medicine, an unrestricted grant from Research to Prevent Blindness, New York, NY (SCP), the Oshman Foundation, Houston, TX (SCP), the William Stamps Farish Fund, Houston, TX (SCP), Hamill Foundation, Houston, TX (SCP) and Sid W Richardson Foundation, Ft Worth, TX (SCP).

\section{Disclosure}

The authors report no conflicts of interest in this work.

\section{References}

1. Doughty MJ, Fonn D, Richter D, Simpson T, Caffery B, Gordon K. A patient questionnaire approach to estimating the prevalence of dry eye symptoms in patients presenting to optometric practices across Canada. Optom Vis Sci. 1997;74(8):624-631.
2. Chia EM, Mitchell P, Rochtchina E, Lee AJ, Maroun R, Wang JJ. Prevalence and associations of dry eye syndrome in an older population: the Blue Mountains Eye Study. Clin Exp Ophthalmol. 2003;31(3):229-232.

3. Ding J, Sullivan DA. Aging and dry eye disease. Exp Gerontol. 2012; 47(7):483-490.

4. Galor A, Feuer W, Lee DJ, et al. Prevalence and risk factors of dry eye syndrome in a United States veterans affairs population. Am J Ophthalmol. 2011;152(3):377-384.

5. Guillon M, Maissa C. Tear film evaporation - effect of age and gender. ContLens Anterior Eye. 2010;33(4):171-175.

6. Guo B, Lu P, Chen X, Zhang W, Chen R. Prevalence of dry eye disease in Mongolians at high altitude in China: the Henan eye study. Ophthalmic Epidemiol. 2010;17(4):234-241.

7. McCarty CA, Bansal AK, Livingston PM, Stanislavsky YL, Taylor HR. The epidemiology of dry eye in Melbourne, Australia. Ophthalmology. 1998;105(6):1114-1119.

8. Moss SE, Klein R, Klein BE. Prevalence of and risk factors for dry eye syndrome. Arch Ophthalmol. 2000;118(9):1264-1268.

9. Schaumberg DA, Dana R, Buring JE, Sullivan DA. Prevalence of dry eye disease among US men: estimates from the Physicians' Health Studies. Arch Ophthalmol. 2009;127(6):763-768.

10. Schaumberg DA, Sullivan DA, Buring JE, Dana MR. Prevalence of dry eye syndrome among US women. Am J Ophthalmol. 2003;136(2): 318-326.

11. Schein OD, Hochberg MC, Munoz B, et al. Dry eye and dry mouth in the elderly: a population-based assessment. Arch Intern Med. 1999; 159(12):1359-1363.

12. Schein OD, Munoz B, Tielsch JM, Bandeen-Roche K, West S. Prevalence of dry eye among the elderly. Am J Ophthalmol. 1997;124(6): 723-728.

13. Xu L, You QS, Wang YX, Jonas JB. Associations between gender, ocular parameters and diseases: the Beijing Eye study. Ophthalmic Res. 2011;45(4):197-203.

14. Asiedu K, Kyei S, Boampong F, Ocansey S. Symptomatic dry eye and its associated factors: a study of university undergraduate students in Ghana. Eye Contact Lens. Epub 2016 Mar 9.

15. Gupta N, Prasad I, Jain R, D’Souza P. Estimating the prevalence of dry eye among Indian patients attending a tertiary ophthalmology clinic. Ann Trop Med Parasitol. 2010;104(3):247-255.

16. Hajiabbasi A, Shenavar Masooleh I, Alizadeh Y, Banikarimi AS, Ghavidel Parsa P. Secondary Sjogren's syndrome in 83 patients with rheumatoid arthritis. Acta Med Iran. 2016;54(7):448-453.

17. Haugen AJ, Peen E, Hulten B, et al. Estimation of the prevalence of primary Sjogren's syndrome in two age-different community-based populations using two sets of classification criteria: the Hordaland Health Study. Scand J Rheumatol. 2008;37(1):30-34.

18. Hikichi T, Yoshida A, Fukui Y. Prevalence of dry eye in Japanese eye centers. Graefes Arch Clin Exp Ophthalmol. 1995;233(9):555-558.

19. Kosrirukvongs P, Ngowyutagon P, Pusuwan P, Koolvisoot A, Nilganuwong S. Prevalence of dry eye syndrome and Sjogren's syndrome in patients with rheumatoid arthritis. JMed Assoc Thai. 2012;95(Suppl 4): S61-S69.

20. Liu NN, Liu L, Li J, Sun YZ. Prevalence of and risk factors for dry eye symptom in mainland China: a systematic review and meta-analysis. J Ophthalmol. 2014;2014:748654.

21. Moss SE, Klein R, Klein BE. Long-term incidence of dry eye in an older population. Optom Vis Sci. 2008;85(8):668-674.

22. Paulsen AJ, Cruickshanks KJ, Fischer ME, et al. Dry eye in the beaver dam offspring study: prevalence, risk factors, and health-related quality of life. Am J Ophthalmol. 2014;157(4):799-806.

23. Pflugfelder SC. Prevalence, burden, and pharmacoeconomics of dry eye disease. Am J Manag Care. 2008;14(3 Suppl): S102-S106.

24. Lienert JP, Tarko L, Uchino M, Christen WG, Schaumberg DA. Longterm natural history of dry eye disease from the patient's perspective. Ophthalmology. 2016;123(2):425-433.

25. Bron AJ, Yokoi N, Gafney E, Tiffany JM. Predicted phenotypes of dry eye: proposed consequences of its natural history. Ocul Surf. 2009;7(2):78-92. 
26. de Paiva CS, Lindsey JL, Pflugfelder SC. Assessing the severity of keratitis sicca with videokeratoscopic indices. Ophthalmology. 2003;110(6):1102-1109.

27. Kojima T, Ishida R, Dogru M, et al. A new noninvasive tear stability analysis system for the assessment of dry eyes. Invest Ophthalmol Vis Sci. 2004;45(5):1369-1374.

28. Liu Z, Pflugfelder SC. Corneal surface regularity and the effect of artificial tears in aqueous tear deficiency. Ophthalmology. 1999; 106(5):939-943.

29. Chotikavanich S, de Paiva CS, Li de Q, et al. Production and activity of matrix metalloproteinase-9 on the ocular surface increase in dysfunctional tear syndrome. Invest Ophthalmol Vis Sci. 2009;50(7): 3203-3209.

30. Rolando M, Iester M, Macri A, Calabria G. Low spatial-contrast sensitivity in dry eyes. Cornea. 1998;17(4):376-379.

31. Tuisku IS, Konttinen YT, Konttinen LM, Tervo TM. Alterations in corneal sensitivity and nerve morphology in patients with primary Sjogren's syndrome. Exp Eye Res. 2008;86(6):879-885.

32. Buchholz P, Steeds CS, Stern LS, et al. Utility assessment to measure the impact of dry eye disease. Ocul Surf. 2006;4(3):155-161.

33. Zhang Y, Lin T, Jiang A, Zhao N, Gong L. Vision-related quality of life and psychological status in Chinese women with Sjogren's syndrome dry eye: a case-control study. BMC Womens Health. 2016;16(1):75.

34. Reddy P, Grad O, Rajagopalan K. The economic burden of dry eye: a conceptual framework and preliminary assessment. Cornea. 2004; 23(8):751-761.

35. Yu J, Asche CV, Fairchild CJ. The economic burden of dry eye disease in the United States: a decision tree analysis. Cornea. 2011;30(4): 379-387.

36. Wan KH, Chen LJ, Young AL. Depression and anxiety in dry eye disease: a systematic review and meta-analysis. Eye (Lond). 2016; 30(12):1558-1567.

37. Mantelli F, Mauris J, Argueso P. The ocular surface epithelial barrier and other mechanisms of mucosal protection: from allergy to infectious diseases. Curr Opin Allergy Clin Immunol. 2013;13(5):563-568.

38. Pflugfelder SC, Farley W, Luo L, et al. Matrix metalloproteinase-9 knockout confers resistance to corneal epithelial barrier disruption in experimental dry eye. Am J Pathol. 2005;166(1):61-71.

39. Ochieng J, Fridman R, Nangia-Makker P, et al. Galectin-3 is a novel substrate for human matrix metalloproteinases-2 and -9. Biochemistry. 1994;33(47):14109-14114.

40. Blalock TD, Spurr-Michaud SJ, Tisdale AS, Gipson IK. Release of membrane-associated mucins from ocular surface epithelia. Invest Ophthalmol Vis Sci. 2008;49(5):1864-1871.

41. Twining SS, Schulte DP, Zhou X, Wilson PM, Fish BL, Moulder JE. Changes in rat corneal matrix metalloproteinases and serine proteinases under vitamin A deficiency. Curr Eye Res. 1997;16(2):158-165.

42. Wiechmann AF, Ceresa BP, Howard EW. Diurnal variation of tight junction integrity associates inversely with matrix metalloproteinase expression in Xenopus laevis corneal epithelium: implications for circadian regulation of homeostatic surface cell desquamation. PLoS One. 2014;9(11):e113810.

43. Garrana RM, Zieske JD, Assouline M, Gipson IK. Matrix metalloproteinases in epithelia from human recurrent corneal erosion. Invest Ophthalmol Vis Sci. 1999;40(6):1266-1270.

44. Sakimoto T, Sawa M. Metalloproteinases in corneal diseases: degradation and processing. Cornea. 2012;31(Suppl 1):S50-S56.

45. Sack RA, Beaton A, Sathe S, Morris C, Willcox M, Bogart B. Towards a closed eye model of the pre-ocular tear layer. Prog Retin Eye Res. 2000;19(6):649-668.

46. Afonso AA, Sobrin L, Monroy DC, Selzer M, Lokeshwar B, Pflugfelder SC. Tear fluid gelatinase B activity correlates with IL-1alpha concentration and fluorescein clearance in ocular rosacea. Invest Ophthalmol Vis Sci. 1999;40(11):2506-2512.

47. Corrales RM, Stern ME, De Paiva CS, Welch J, Li DQ, Pflugfelder SC. Desiccating stress stimulates expression of matrix metalloproteinases by the corneal epithelium. Invest Ophthalmol Vis Sci. 2006;47(8): 3293-3302.
48. De Paiva CS, Corrales RM, Villarreal AL, et al. Apical corneal barrier disruption in experimental murine dry eye is abrogated by methylprednisolone and doxycycline. Invest Ophthalmol Vis Sci. 2006; 47(7):2847-2856.

49. Pflugfelder SC, Tseng SC, Sanabria O, et al. Evaluation of subjective assessments and objective diagnostic tests for diagnosing tear-film disorders known to cause ocular irritation. Cornea. 1998;17(1):38-56.

50. de Paiva CS, Yoon KC, Pangelinan SB, et al. Cleavage of functional IL-2 receptor alpha chain (CD25) from murine corneal and conjunctival epithelia by MMP-9. J Inflamm (Lond). 2009;6:31.

51. de Paiva CS, Chotikavanich S, Pangelinan SB, et al. IL-17 disrupts corneal barrier following desiccating stress. Mucosal Immunol. 2009;2(3):243-253

52. Ochieng J, Green B, Evans S, James O, Warfield P. Modulation of the biological functions of galectin-3 by matrix metalloproteinases. Biochim Biophys Acta. 1998;1379(1):97-106.

53. Stern ME, Gao J, Siemasko KF, Beuerman RW, Pflugfelder SC. The role of the lacrimal functional unit in the pathophysiology of dry eye. Exp Eye Res. 2004;78(3):409-416.

54. Leonardi A, Brun P, Abatangelo G, Plebani M, Secchi AG. Tear levels and activity of matrix metalloproteinase (MMP)-1 and MMP-9 in vernal keratoconjunctivitis. Invest Ophthalmol Vis Sci. 2003;44(7): 3052-3058.

55. Sobrin L, Liu Z, Monroy DC, et al. Regulation of MMP-9 activity in human tear fluid and corneal epithelial culture supernatant. Invest Ophthalmol Vis Sci. 2000;41(7):1703-1709.

56. Bauskar A, Mack WJ, Mauris J, et al. Clusterin seals the ocular surface barrier in mouse dry eye. PLoS One. 2015;10(9):e0138958.

57. Fini ME, Bauskar A, Jeong S, Wilson MR. Clusterin in the eye: an old dog with new tricks at the ocular surface. Exp Eye Res. 2016;147: $57-71$.

58. Enriquez-de-Salamanca A, Castellanos E, Stern ME, et al. Tear cytokine and chemokine analysis and clinical correlations in evaporativetype dry eye disease. Mol Vis. 2010;16:862-873.

59. Solomon A, Dursun D, Liu Z, Xie Y, Macri A, Pflugfelder SC. Proand anti-inflammatory forms of interleukin-1 in the tear fluid and conjunctiva of patients with dry-eye disease. Invest Ophthalmol Vis Sci. 2001;42(10):2283-2292

60. Stewart P, Chen Z, Farley W, Olmos L, Pflugfelder SC. Effect of experimental dry eye on tear sodium concentration in the mouse. Eye Contact Lens. 2005;31(4):175-178.

61. Pflugfelder SC. Tear dysfunction and the cornea: LXVIII Edward Jackson Memorial Lecture. Am J Ophthalmol. 2011;152(6):900-909.e901.

62. Li DQ, Shang TY, Kim HS, Solomon A, Lokeshwar BL, Pflugfelder SC. Regulated expression of collagenases MMP-1, -8 , and -13 and stromelysins MMP-3, -10 , and -11 by human corneal epithelial cells. Invest Ophthalmol Vis Sci. 2003;44(7):2928-2936.

63. Luo L, Li DQ, Corrales RM, Pflugfelder SC. Hyperosmolar saline is a proinflammatory stress on the mouse ocular surface. Eye Contact Lens. 2005;31(5):186-193.

64. Li DQ, Chen Z, Song XJ, Farley W, Pflugfelder SC. Hyperosmolarity stimulates production of MMP-9, IL-1á and TNF- by human corneal epithelial cells via a c-Jun NH 2- terminal kinase pathway. Invest Ophthalmol Vis Sci. 2002;43(13):1981.

65. Li DQ, Lokeshwar BL, Solomon A, Monroy D, Ji Z, Pflugfelder SC. Regulation of MMP-9 production by human corneal epithelial cells. Exp Eye Res. 2001;73(4):449-459.

66. Iovieno A, Lambiase A, Micera A, Stampachiacchiere B, Sgrulletta R, Bonini S. In vivo characterization of doxycycline effects on tear metalloproteinases in patients with chronic blepharitis. Eur J Ophthalmol. 2009;19(5):708-716.

67. Sambursky R, Davitt WF 3rd, Friedberg M, Tauber S. Prospective, multicenter, clinical evaluation of point-of-care matrix metalloproteinase-9 test for confirming dry eye disease. Cornea. 2014;33(8):812-818.

68. Sambursky R, Davitt WF 3rd, Latkany R, et al. Sensitivity and specificity of a point-of-care matrix metalloproteinase 9 immunoassay for diagnosing inflammation related to dry eye. JAMA Ophthalmology. 2013;131(1):24-28. 
69. Messmer EM, von Lindenfels V, Garbe A, Kampik A. Matrix metalloproteinase 9 testing in dry eye disease using a commercially available point-of-care immunoassay. Ophthalmology. 2016;123(11): 2300-2308.

70. Lanza NL, McClellan AL, Batawi H, et al. Dry eye profiles in patients with a positive elevated surface matrix metalloproteinase 9 point-ofcare test versus negative patients. Ocul Surf. 2016;14(2):216-223.

71. VanDerMeid KR, Su SP, Ward KW, Zhang JZ. Correlation of tear inflammatory cytokines and matrix metalloproteinases with four dry eye diagnostic tests. Invest Ophthalmol Vis Sci. 2012;53(3):1512-1518.

72. Aragona P, Aguennouz M, Rania L, et al. Matrix metalloproteinase 9 and transglutaminase 2 expression at the ocular surface in patients with different forms of dry eye disease. Ophthalmology. 2015;122(1): $62-71$.

73. Acera A, Vecino E, Duran JA. Tear MMP-9 levels as a marker of ocular surface inflammation in conjunctivochalasis. Invest Ophthalmol Vis Sci. 2013;54(13):8285-8291.

74. Arafat SN, Suelves AM, Spurr-Michaud S, et al. Neutrophil collagenase, gelatinase, and myeloperoxidase in tears of patients with StevensJohnson syndrome and ocular cicatricial pemphigoid. Ophthalmology 2014;121(1):79-87.

75. Aluri HS, Kublin CL, Thotakura S, et al. Role of matrix metalloproteinases 2 and 9 in lacrimal gland disease in animal models of Sjogren's syndrome. Invest Ophthalmol Vis Sci. 2015;56(9):5218-5228.

76. Luo L, Li DQ, Doshi A, Farley W, Corrales RM, Pflugfelder SC. Experimental dry eye stimulates production of inflammatory cytokines and MMP-9 and activates MAPK signaling pathways on the ocular surface. Invest Ophthalmol Vis Sci. 2004;45(12):4293-4301.

77. De Paiva CS, Corrales RM, Villarreal AL, et al. Corticosteroid and doxycycline suppress MMP-9 and inflammatory cytokine expression, MAPK activation in the corneal epithelium in experimental dry eye. Exp Eye Res. 2006;83(3):526-535.

78. Fini ME, Cui TY, Mouldovan A, Grobelny D, Galardy RE, Fisher SJ. An inhibitor of the matrix metalloproteinase synthesized by rabbit corneal epithelium. Invest Ophthalmol Vis Sci. 1991;32(11):2997-3001.

79. Sotozono C HeJ, Tei M, Honma Y, Kinoshita S. Effect of metalloproteinase inhibitor on corneal cytokine expression after alkali injury. Invest Ophthalmol Vis Sci. 1999;40(10):2430-2434.

80. Zhang H, Li C, Baciu PC. Expression of integrins and MMPs during alkaline-burn-induced corneal angiogenesis. Invest Ophthalmol Vis Sci. 2002;43(4):955-962.

81. Sakimoto T, Shoji J, Kanno H, Sawa M. Gelatinase expression in ocular surface disorders. Jpn J Ophthalmol. 2004;48(1):17-22.

82. Bian F, Pelegrino FS, Pflugfelder SC, Volpe EA, Li DQ, de Paiva CS. Desiccating stress-induced MMP production and activity worsens wound healing in alkali-burned corneas. Invest Ophthalmol Vis Sci. 2015;56(8):4908-4918

83. Bian F, Shin CS, Wang C, Pflugfelder SC, Acharya G, De Paiva CS. Dexamethasone drug eluting nanowafers control inflammation in alkali-burned corneas associated with dry eye. Invest Ophthalmol Vis Sci. 2016;57(7):3222-3230.

84. Bian F, Wang C, Tukler-Henriksson J, et al. MMP-8 is critical for dexamethasone therapy in alkali-burned corneas under dry eye conditions. J Cell Physiol. 2016;231(11):2506-2516.

85. Bian F, Pelegrino FS, Tukler Henriksson J, et al. Differential effects of dexamethasone and doxycycline on inflammation and MMP production in alkali-burned corneas associated with dry eye. Ocul Surf. 2016;14(2):242-254.

86. Boyle JR, McDermott E, Crowther M, Wills AD, Bell PR, Thompson MM. Doxycycline inhibits elastin degradation and reduces metalloproteinase activity in a model of aneurysmal disease. J Vasc Surg. 1998;27(2):354-361.

87. Brown DL, Desai KK, Vakili BA, Nouneh C, Lee HM, Golub LM. Clinical and biochemical results of the metalloproteinase inhibition with subantimicrobial doses of doxycycline to prevent acute coronary syndromes (MIDAS) pilot trial. Arterioscler Thromb Vasc Biol. 2004;24(4):733-738.
88. Chowdhury MH, Moak SA, Rifkin BR, Greenwald RA. Effect of tetracyclines which have metalloproteinase inhibitory capacity on basal and heparin-stimulated bone resorption by chick osteoclasts. Agents Actions. 1993;40(1-2):124-128.

89. Gilbertson-Beadling S, Powers EA, Stamp-Cole M, et al. The tetracycline analogs minocycline and doxycycline inhibit angiogenesis in vitro by a non-metalloproteinase-dependent mechanism. Cancer Chemother Pharmacol. 1995;36(5):418-424.

90. Golub LM, Lee HM, Greenwald RA, et al. A matrix metalloproteinase inhibitor reduces bone-type collagen degradation fragments and specific collagenases in gingival crevicular fluid during adult periodontitis. Inflamm Res. 1997;46(8):310-319.

91. Hanemaaijer R, Visser H, Koolwijk P, et al. Inhibition of MMP synthesis by doxycycline and chemically modified tetracyclines (CMTs) in human endothelial cells. Adv Dent Res. 1998;12(2):114-118.

92. Zhang Z, Yang WZ, Zhu ZZ, et al. Therapeutic effects of topical doxycycline in a benzalkonium chloride-induced mouse dry eye model. Invest Ophthalmol Vis Sci. 2014;55(5):2963-2974.

93. Kim HS, Luo L, Pflugfelder SC, Li DQ. Doxycycline inhibits TGFbeta1-induced MMP-9 via Smad and MAPK pathways in human corneal epithelial cells. Invest Ophthalmol Vis Sci. 2005;46(3):840-848.

94. Li DQ, Chen Z, Song XJ, Luo L, Pflugfelder SC. Stimulation of matrix metalloproteinases by hyperosmolarity via a JNK pathway in human corneal epithelial cells. Invest Ophthalmol Vis Sci. 2004;45(12):4302-4311.

95. Li DQ, Luo L, Chen Z, Kim HS, Song XJ, Pflugfelder SC. JNK and ERK MAP kinases mediate induction of IL-1beta, TNF-alpha and IL-8 following hyperosmolar stress in human limbal epithelial cells. Exp Eye Res. 2006;82(4):588-596.

96. Beardsley RM, De Paiva CS, Power DF, Pflugfelder SC. Desiccating stress decreases apical corneal epithelial cell size-modulation by the metalloproteinase inhibitor doxycycline. Cornea. 2008;27(8):935-940.

97. Chang E, McClellan AJ, Farley WJ, Li DQ, Pflugfelder SC, De Paiva CS. Biodegradable PLGA-based drug delivery systems for modulating ocular surface disease under experimental murine dry eye. J Clin Exp Ophthalmol. 2011;2(11)

98. Bian F, Pelegrino FS, Henriksson JT, et al. Differential effects of dexamethasone and doxycycline on inflammation and MMP production in murine alkali-burned corneas associated with dry eye. Ocul Surf. 2016;14(2):242-254.

99. Dursun D, Kim MC, Solomon A, Pflugfelder SC. Treatment of recalcitrant recurrent corneal erosions with inhibitors of matrix metalloproteinase-9, doxycycline and corticosteroids. Am J Ophthalmol. 2001;132(1):8-13.

100. Dursun D, Piniella AM, Pflugfelder SC. Pseudokeratoconus caused by rosacea. Cornea. 2001;20(6):668-669.

101. Arman A, Demirseren DD, Takmaz T. Treatment of ocular rosacea: comparative study of topical cyclosporine and oral doxycycline. Int J Ophthalmol. 2015;8(3):544-549.

102. Doughty MJ. On the prescribing of oral doxycycline or minocycline by UK optometrists as part of management of chronic Meibomian Gland Dysfunction (MGD). Cont Lens Anterior Eye. 2016;39(1):2-8.

103. Gu Y, Walker C, Ryan ME, Payne JB, Golub LM. Non-antibacterial tetracycline formulations: clinical applications in dentistry and medicine. J Oral Microbiol. 2012;4.

104. Li DQ, Zhou N, Zhang L, Ma P, Pflugfelder SC. Suppressive effects of azithromycin on zymosan-induced production of proinflammatory mediators by human corneal epithelial cells. Invest Ophthalmol Vis Sci. 2010;51(11):5623-5629.

105. Zhang L, Su Z, Zhang Z, Lin J, Li DQ, Pflugfelder SC. Effects of azithromycin on gene expression profiles of proinflammatory and anti-inflammatory mediators in the eyelid margin and conjunctiva of patients with meibomian gland disease. JAMA Ophthalmol. 2015;133(10):1117-1123.

106. Deng R, Su Z, Hua X, Zhang Z, Li DQ, Pflugfelder SC. Osmoprotectants suppress the production and activity of matrix metalloproteinases induced by hyperosmolarity in primary human corneal epithelial cells. Mol Vis. 2014;20:1243-1252. 
107. Coursey TG, Henriksson JT, Barbosa FL, de Paiva CS, Pflugfelder SC. Interferon-gamma-induced unfolded protein response in conjunctival goblet cells as a cause of mucin deficiency in Sjogren syndrome. Am J Pathol. 2016;186(6):1547-1558.

108. Coursey TG, Henriksson JT, Marcano DC, et al. Dexamethasone nanowafer as an effective therapy for dry eye disease. $J$ Control Release. 2015;213:168-174.

109. Marsh P, Pflugfelder SC. Topical nonpreserved methylprednisolone therapy for keratoconjunctivitis sicca in Sjogren syndrome. Ophthalmology. 1999;106(4):811-816.

110. Pflugfelder SC, Maskin SL, Anderson B, et al. A randomized, doublemasked, placebo-controlled, multicenter comparison of loteprednol etabonate ophthalmic suspension, $0.5 \%$, and placebo for treatment of keratoconjunctivitis sicca in patients with delayed tear clearance. Am J Ophthalmol. 2004;138(3):444-457.

111. Sheppard JD, Scoper SV, Samudre S. Topical loteprednol pretreatment reduces cyclosporine stinging in chronic dry eye disease. $\mathrm{JOcul}$ Pharmacol Ther. 2011;27(1):23-27.

112. Moore QL, de Paiva CS, Pflugfelder SC. Effects of dry eye therapies on environmentally induced ocular surface disease. Am J Ophthalmol. 2015;160(1):135-142.

113. Pinto-Fraga J, Lopez-Miguel A, Gonzalez-Garcia MJ, et al. Topical fluorometholone protects the ocular surface of dry eye patients from desiccating stress: a randomized controlled clinical trial. Ophthalmology. 2016;123(1):141-153.

114. Lopez-Miguel A, Teson M, Martin-Montanez V, et al. Dry eye exacerbation in patients exposed to desiccating stress under controlled environmental conditions. Am J Ophthalmol. 2014;157(4): 788-798.

115. Borel JF. Ciclosporin and its future. Prog Allergy. 1986;38:9-18.

116. Stahelin HF. The history of cyclosporin A (Sandimmune) revisited: another point of view. Experientia. 1996;52(1):5-13.

117. Kaswan RL, Salisbury MA, Ward DA. Spontaneous canine keratoconjunctivitis sicca. A useful model for human keratoconjunctivitis sicca: treatment with cyclosporine eye drops. Arch Ophthalmol. 1989;107(8):1210-1216.

118. Sall K, Stevenson OD, Mundorf TK, Reis BL. Two multicenter, randomized studies of the efficacy and safety of cyclosporine ophthalmic emulsion in moderate to severe dry eye disease. CsA Phase 3 Study Group. Ophthalmology. 2000;107(4):631-639.

119. Wan KH, Chen LJ, Young AL. Efficacy and safety of topical $0.05 \%$ cyclosporine eye drops in the treatment of dry eye syndrome: a systematic review and meta-analysis. Ocul Surf. 2015;13(3): 213-225.

120. Pflugfelder SC, De Paiva CS, Villarreal AL, Stern ME. Effects of sequential artificial tear and cyclosporine emulsion therapy on conjunctival goblet cell density and transforming growth factor-beta2 production. Cornea. 2008;27(1):64-69.
121. de Paiva CS, Raince JK, McClellan AJ, et al. Homeostatic control of conjunctival mucosal goblet cells by NKT-derived IL-13. Mucosal Immunol. 2011;4(4):397-408.

122. Xiao W, Xu GT, Zhang J, Zhang J, Zhang Y, Ye W. FTY720 ameliorates dry eye disease in NOD mice: involvement of leukocytes inhibition and goblet cells regeneration in ocular surface tissue. Exp Eye Res. 2015;138:145-152.

123. Liu S, Dozois MD, Chang CN, et al. Prolonged ocular retention of mucoadhesive nanoparticle eye drop formulation enables treatment of eye diseases using significantly reduced dosage. Mol Pharm. 2016;13(9):2897-2905.

124. Kim YJ, Ryu JS, Park SY, et al. Comparison of topical application of TSG-6, cyclosporine, and prednisolone for treating dry eye. Cornea. 2016;35(4):536-542.

125. Kunert KS, Tisdale AS, Stern ME, Smith JA, Gipson IK. Analysis of topical cyclosporine treatment of patients with dry eye syndrome: effect on conjunctival lymphocytes. ArchOphthalmol. 2000;118(11):1489-1496.

126. Strong B, Farley W, Stern ME, Pflugfelder SC. Topical cyclosporine inhibits conjunctival epithelial apoptosis in experimental murine keratoconjunctivitis sicca. Cornea. 2005;24(1):80-85.

127. Contreras-Ruiz L, Masli S. Immunomodulatory cross-talk between conjunctival goblet cells and dendritic cells. PLoS One. 2015; 10(3): $\mathrm{e} 0120284$

128. Xiao Y, Coursey TG, Li DQ, de Paiva CS, Tukler Henriksson J, Pflugfelder SC. Conjunctival goblet cells modulate dendritic cell maturation and retinoic acid producing capacity. Invest Ophthalmol Vis Sci. 2016;57(426).

129. Kim YH, Jung JC, Jung SY, Kim YI, Lee KW, Park YJ. Cyclosporine a downregulates MMP-3 and MMP-13 expression in cultured pterygium fibroblasts. Cornea. 2015;34(9):1137-1143.

130. Fu MM, Fu E, Kuo PJ, et al. Gelatinases and extracellular matrix metalloproteinase inducer are associated with cyclosporin-A-induced attenuation of periodontal degradation in rats. J Periodontol. 2015; 86(1):82-90.

131. Kuo PJ, Tu HP, Chin YT, et al. Cyclosporine-A inhibits MMP-2 and -9 activities in the presence of Porphyromonas gingivalis lipopolysaccharide: an experiment in human gingival fibroblast and U937 macrophage co-culture. J Periodontal Res. 2012;47(4):431-438.

132. Gurdal C, Genc I, Sarac O, Gonul I, Takmaz T, Can I. Topical cyclosporine in thyroid orbitopathy-related dry eye: clinical findings, conjunctival epithelial apoptosis, and MMP-9 expression. Curr Eye Res. 2010;35(9):771-777.

133. Sambursky R. Presence or absence of ocular surface inflammation directs clinical and therapeutic management of dry eye. Clin Ophthalmol. 2016;10:2337-2343.

134. Jeong S, Ledee DR, Gordon GM, et al. Interaction of clusterin and matrix metalloproteinase-9 and its implication for epithelial homeostasis and inflammation. Am J Pathol. 2012;180(5):2028-2039.
Metalloproteinases In Medicine

\section{Publish your work in this journal}

Metalloproteinases In Medicine is an international, peer reviewed, open access journal that aims to provide a platform for the discussion and dissemination of knowledge about the role that metalloproteinases - such as matrix metalloproteinases (MMP), ADAMs, ADAMTSs, and astacins, as well as their inhibitors - play in diseases.

\section{Dovepress}

The manuscript management system is completely online and includes a very quick and fair peer review system, which is all easy to use. Visit http://www.dovepress.com/testimonials.php to read real quotes from published authors. 